\title{
Projeto de SENTENÇAS ESTRANGEIRAS DA CONFERÊNCIA DE HAIA: POR UM REGIME GLOBAL DE CIRCULAÇÃO INTERNACIONAL DE SENTENÇAS EM MATÉRIA CIVIL E COMERCIAL
}

\author{
NADIA DE ARAUJO ${ }^{\dagger}$ \\ MARCELO DE NARDI ${ }^{\dagger \dagger}$
}

ReSUMO: A Conferência da Haia para o Direito Internacional Privado está promovendo a adoção de regras voltadas para a minimização dos entraves à circulação internacional de sentenças. O objetivo do Projeto de Sentenças iniciado nos anos noventa do século vinte é mitigar as incertezas e riscos associados ao comércio internacional por meio do estabelecimento de um sistema facilitado e seguro de circulação internacional de sentenças. $\mathrm{O}$ artigo tem por finalidade preservar o histórico deste momento da evolução das negociações no âmbito da Conferência, além de especificar questões de cunho técnico discutidas no projeto que possam ser de interesse geral para aqueles envolvidos no tema da jurisdição internacional.

Palavras-Chave: Conferência da Haia; Projeto de Sentenças; Homologação de Sentenças Estrangeiras; Cooperação Jurídica Internacional.

\footnotetext{
${ }^{\dagger}$ Advogada e Professora de Direito Internacional Privado da Pontifícia Universidade Católica do Rio de Janeiro. Doutora em Direito Internacional pela Universidade de São Paulo.

${ }^{\dagger}$ Juiz Federal e Professor de Direito Internacional do Comércio da Universidade do Vale dos Sinos. Doutor em Direito Privado pela Universidade Federal do Rio Grande do Sul.
} 


\begin{abstract}
The Hague Conference on Private International Law is promoting the adoption of rules designed to circumvent usual obstacles to the international circulation of judgments. The Judgments Project initiated in the nineties aims at mitigating uncertainties and risks associated with the international commerce by setting forth a simple and safe system according to which foreign judgments may circulate from country to country. The purpose of this article is to preserve the historical moment of the negotiations taking place at the Hague, as well as to pinpoint some technical issues raised in the course of the project that may be of general interest to those involved in the subject of international jurisdiction.
\end{abstract}

KeYWORDS: Hague Conference; Judgments Project; Recognition and Enforcement of Foreign Judgments; International Legal Cooperation. 


\section{SUMÁRIO:}

I. INTRODUÇão........................................................................................710

II. Projeto de SentenÇas e o Modelo Brasileiro ........................712

1. Início do Projeto e seu Objetivo................................................712

2. O Modelo Brasileiro.....................................................................714

3. A Fase de Negociações no GT ...............................................718

III. A Comissão ESPeCial e os Principais Pontos Discutidos ....720

1. O Anteprojeto: análise de certos aspectos ..............................720

2. Bases Indiretas de Jurisdição...................................................722

3. Bases Exclusivas de Jurisdição

e Causas de Recusa de Reconhecimento ...............................725

IV. QUESTIONÁRIO SOBRE TEMAS DE INTERESSE DO BRASIL................726

1. As Perguntas...............................................................................726

2. As Respostas ............................................................................729

V. ESCOPO DO ANTEPROJETO DE CONVENÇÃO:

o QUE SÃO “QUESTÕes CÍvEIS E COMERCIAIS"? .............................730

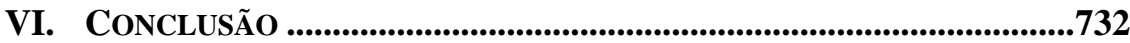

VII. REFERÊNCIAS.............................................................................................734

\section{TABLE OF CONTENTS:}

I. INTRODUCTION ……………………………............................................710

II. JUDGMENTS PROJETCT AND THE BRAZILIAN MODEL ......................712

1. Project Start and its Objective................................................712

2. The Brazilian Model ................................................................714

3. The Negotiation Phase in the WG ........................................718

III. The SPeCial Commission AND the Main PoinTs DiscusSed ...720

1. The Preliminary Draft: analysis of some aspects .................720

2. Indirect Bases of Jurisdiction ...................................................722

3. Exclusive Bases of Jurisdiction and Recognition Refusal Causes............................................725

IV. QUESTIONNAIRE ON BRAZIL'S INTEREST TOPICS ............................726

1. The Questions...............................................................................726

2. The Answers..............................................................................729

V. SCOPE OF CONVENTION'S PRELIMINARY DRAFT:

WHAT ARE "CIVIL AND COMMERCIAL ISSUES"?..............................730

VI. CONCLUSION .......................................................................................732

VII. REFERENCES ..............................................................................................734 


\section{INTRODUÇÃO}

O funcionamento eficiente do comércio internacional não pode dispensar o elemento de confiança entre as partes, que realizam seus negócios através de contratos internacionais, na maioria das vezes à distância. Nem sempre essas relações internacionais chegam a bom termo, o que gera um número significativo de litígios em que as partes estão em países diversos. Isso implica a necessidade de litigar judicialmente em um país, pretendendo que os efeitos da sentença se produzam em outro. Se a execução da sentença doméstica é automaticamente garantida pelo sistema jurídico que a proferiu, não se pode dizer o mesmo de uma sentença estrangeira, que fica à mercê das regras do foro em que se pretende executá-la.

A dificuldade de execução de uma sentença no estrangeiro pode estar causando prejuízos a contratantes, nas situações em que os contratos são descumpridos e os custos de litigar e executar supera o valor de potencial indenização. A falta de efetividade das regras de Direito nessas condições abre a possibilidade de fraudes e ilícitos que se valem da boa-fé comercial, diante da certeza de que um inadimplemento contratual não será objeto de disputa judicial. A par dessa questão contratual, também os casos de responsabilidade civil, em que a disputa emerge de um ilícito, não veem facilitação para liquidar a indenização que seja outorgada, impedindo que a penalização seja efetiva contra o infrator.

São conhecidos os problemas advindos da necessidade de produção de efeitos das sentenças estrangeiras em Estado diverso daquele em que proferida. Há marcante diferença para as partes em optar por solucionar suas controvérsias internacionais pela via arbitral ou pela via judicial, eis que os laudos arbitrais estrangeiros têm sua circulação e execução facilitada pela Convenção de Nova Iorque ${ }^{1}$, mas em contrapartida a arbitragem implica custos de litigar elevados. As decisões judiciais, em especial em casos de responsabilidade civil, não contam com um diploma internacional a facilitar sua circulação. A posição de um indivíduo ou empresa que participa de negócios transnacionais, portanto, fica caracterizada por um alto nível de incerteza quanto à produção de efeitos de uma sentença estrangeira que lhe seja favorável, acrescendo riscos à transação.

${ }^{1}$ Convenção de Nova Iorque sobre o Reconhecimento e a Execução de Sentenças Arbitrais Estrangeiras, internalizada no Brasil pelo Decreto 4.311, de 23 de julho de 2002.

2 JOURNAL OF INSTITUTIONAL STUDIES 2 (2016) 
A Conferência da Haia para o Direito Internacional Privado², organização internacional que tem por objetivo promover a uniformização e a harmonização do Direito Internacional Privado, está preocupada em elaborar regras que minimizem os entraves à circulação internacional de sentenças. O objetivo do Projeto de Sentenças iniciado pela conferência nos anos noventa do século vinte é mitigar a incerteza, e consequentemente o risco associado ao comércio internacional, por meio do estabelecimento de um sistema facilitado e seguro de circulação internacional de sentenças. A afirmação internacional do efeito da decisão judicial produzirá maior estímulo ao cumprimento das regras de direito que tenham sido violadas, favorecendo a cobrança das indenizações correspondentes.

De 1ํa 9 de junho de 2016, a Comissão Especial sobre o Projeto de Sentenças da Conferência da Haia para o Direito Internacional Privado se reuniu pela primeira vez, na cidade da Haia, Holanda, no Palácio da Paz, sede da Academia de Direito Internacional ${ }^{3}$. De acordo com o mandato do Conselho de Assuntos Gerais da Conferência da Haia, a Comissão Especial tem por missão propor uma convenção internacional para o reconhecimento e execução de sentenças estrangeiras em matéria civil e comercial. Sua primeira reunião contou com a presença maciça dos Estados Membros e de organizações internacionais". As discussões partiram de anteprojeto proposto por um Grupo de Trabalho ("GT"), resultado de quatro anos de encontros 5 .

Ao longo da reunião todos os itens do anteprojeto foram discutidos e chegou-se a um novo texto contendo várias emendas ao proposto pelo GT. Também foi elaborado um Aide-Mémoire com os pontos a ser discutidos na próxima reunião, embora não estejam contemplados no novo anteprojeto. A reunião da Comissão Especial foi exitosa e a redação

2 Sobre a Conferência da Haia de Direito Internacional Privado, consultar:

$<$ http://www.hcch.net $>$.

${ }^{3}$ Sobre a Academia da Haia de Direito Internacional, consultar

$<$ http://vredespaleis.nl $>$.

${ }_{4}^{4} 153$ participantes de 53 Estados e 16 organizações internacionais e ONGs, entre elas a ASADIP. A presidência foi exercida por David Goddard, da Nova Zelândia e a Vice-

Presidência por Boni Soares, do Brasil, And Sun, da China e Paul Herrup, dos Estados Unidos. Como Presidente do Comitê de redação, Fausto Pocar, da Italia e como Relatores, Genevieve Saummier, do Canadá e Francisco Garcimartin Alferez, da Espanha.

${ }^{5}$ Para documentação das reuniões do Grupo de Trabalho e outras informações sobre o Projeto de Sentenças, consultar: $<\underline{\text { https://www.hcch.net/en/projects/legislative- }}$ projects/judgments $>$. Acesso em: 23 de novembro 2016. 
do anteprojeto foi bem acolhida pelos participantes. A 2⿳a . Reunião da Comissão Especial ocorrerá em fevereiro de 2017.

Este artigo trata sucintamente do histórico do projeto (i), das discussões e seu resultado, do ponto de vista do interesse brasileiro (ii), e dos temas que merecem a atenção do Brasil (iii). A intenção é preservar o histórico deste momento da evolução das negociações, além de especificar questões de cunho técnico discutidas no projeto, de interesse geral no tema da jurisdição internacional.

\section{Projeto de Sentenças e o Modelo Brasileiro}

\section{Início do Projeto e seu Objetivo}

A Conferência da Haia de Direito Internacional Privado, uma das organizações internacionais mais antigas em atividade, promove desde 2012 o Judgments Project, o Projeto de Sentenças, visando a facilitar a circulação internacional das sentenças através de uma convenção internacional.

O projeto foi desenvolvido por um Grupo de Trabalho formado por representantes de vários países, encarregado de apresentar uma primeira minuta da convenção. O Brasil integrou o Grupo de Trabalho e participou ativamente da iniciativa, sempre enviando representantes para as reuniões. $\mathrm{O}$ resultado do projeto instruiu os trabalhos de uma Comissão Especial, cuja primeira reunião se realizou em junho de 2016.

As negociações tiveram origem em uma proposta apresentada pelos Estados Unidos da América à Conferência da Haia em 1992. Apesar de as negociações terem paralisado em 2001, os estudos desenvolvidos e que refletiam certos temas em consenso resultaram na Convenção sobre Eleição de Foro de 20056, oferecida a ratificação pelos Estados interessados, não estando limitada aos Estados-membros da Conferência da Haia. A Convenção de 2005 entrou em vigor em 2015 com a adesão da União Europeia e do México. Singapura formalizou adesão durante a reunião da Comissão Especial de 2016. Atualmente, está em vias de aprovação em outros Estados.

A aprovação da Convenção sobre Eleição de Foro de 2005 pelo Conselho de Assuntos Gerais da Conferência da Haia de Direito

6 Para mais informações sobre a Convenção sobre Eleição de Foro de 2005, consultar

$<$ https://www.hcch.net/en/instruments/conventions/specialised-sections/choice-of-

court>. Acesso em: 21 de novembro de 2016.

2 JOURNAL OF INSTITUTIONAL STUDIES 2 (2016) 
Internacional Privado encerrou um primeiro ciclo de trabalho do Projeto de Sentenças. No ano de 2011 o Conselho de Assuntos Gerais estabeleceu diretriz para retomada do projeto, dada a receptividade da Convenção de Eleição de Foro e o incremento das expectativas globais sobre o tema. Após recomendação de um grupo de especialistas reunido em 2012, o Conselho estabeleceu um grupo de trabalho que, após cinco reuniões presenciais, finalizou o anteprojeto discutido na Comissão Especial de 2016. O Brasil esteve representado em todas as oportunidades.

O objetivo principal da futura convenção é estabelecer um sistema facilitado de circulação de sentenças estrangeiras, através da fixação de certos parâmetros geralmente aceitos como suficientes para reconhecer que a jurisdição internacional foi exercitada de forma legítima. Para alcançar esse objetivo, deve considerar as importantes diferenças entre os diversos países quanto à aceitação da decisão jurisdicional estrangeira em sua esfera de soberania. A questão foi assim explicitada no relatório explicativo da Convenção sobre Eleição de Foro de 2005:

[...] where the court has jurisdiction on an approved ground, it can hear the case, and the resulting judgment will be recognised and enforced in other Contracting States under the Convention (provided certain other requirements are satisfied). [...]

Em simplificação de valor acadêmico, pode-se classificar em três tipos os sistemas de reconhecimento de sentenças estrangeiras quanto a abertura para admitir a produção de efeitos em território nacional de decisão emanada de outro país:

a) Não se admitem decisões estrangeiras (completamente fechados);

b) Estabelecem-se regras para reconhecimento da jurisdição estrangeira, exigindo certos vínculos entre a autoridade estrangeira e a causa decidida; e

c) Não se verifica a jurisdição estrangeira quanto ao vínculo da autoridade com a causa decidida (completamente abertos).

${ }^{7}$ HARTLEY, Trevor; DOGAUCHI, Masato. Convention of 30 June 2005 on choice of court agreements: explanatory report. Haia: Secretariado Permanente da Conferência Scheveningseweg 6, 2005, p. 785. Disponível em:

$<$ https://assets.hcch.net/docs/a90b5aea-89cf-4541-b7b7-e5e960703845.pdf $>$. Acesso em: 03 de janeiro de 2017.

${ }^{8}$ Conclusões a partir da tabela comparativa sobre regras de jurisdição, preparado pelo Secretariado da HCCH e finalizado em 29 de setembro de 2014. O documento não é público.

2 JOURNAL OF INSTITUTIONAL STUDIES 2 (2016) 
Enquanto em considerável parcela dos países do mundo a admissão de sentença estrangeira impõe a verificação de que a autoridade que a proferiu tinha vinculação fática com a causa decidida, no caso brasileiro não se exercita esse "controle indireto da jurisdição estrangeira", como se verá a seguir.

\section{O Modelo Brasileiro}

A legislação brasileira, consagrada pela atual jurisprudência do Superior Tribunal de Justiça, indica que o Brasil se aproxima do modelo c, acima descrito. O Superior Tribunal de Justiça (STJ) exerce o controle verificando o requisito da autoridade competente ${ }^{9}$. Ao fazê-lo, limita-se a examinar se a autoridade estrangeira que proferiu a decisão em processo de homologação não invadiu a competência exclusiva do juiz nacional, prevista no art. 23 do Código de Processo Civil de 2015 ${ }^{10}$.

De ressaltar que o modelo brasileiro de admissão de efeitos na jurisdição nacional de decisão de autoridade estrangeira segue o sistema de delibação concentrado, de responsabilidade de um único órgão de natureza jurisdicional, o Superior Tribunal de Justiça (STJ) ${ }^{11}$. A história da distribuição legislativa dessa competência interna registra centenária

\footnotetext{
${ }^{9}$ Inc. I do art. 963 do Código de Processo Civil de 2015 (Lei no 13.105/2015, vigência em 18 de março de 2016): “Art. 963. Constituem requisitos indispensáveis à homologação da decisão: I - ser proferida por autoridade competente; [...]"

${ }^{10}$ Assim está redigido o art. 23: "Art. 23. Compete à autoridade judiciária brasileira, com exclusão de qualquer outra: I - conhecer de ações relativas a imóveis situados no Brasil; II - em matéria de sucessão hereditária, proceder à confirmação de testamento particular e ao inventário e à partilha de bens situados no Brasil, ainda que o autor da herança seja de nacionalidade estrangeira ou tenha domicílio fora do território nacional; III - em divórcio, separação judicial ou dissolução de união estável, proceder à partilha de bens situados no Brasil, ainda que o titular seja de nacionalidade estrangeira ou tenha domicílio fora do território nacional."

${ }^{11}$ Nos termos da al. $i$ do inc. I do art. 105 da Constituição: "Art. 105. Compete ao Superior Tribunal de Justiça: I - processar e julgar, originariamente: [...] i) a homologação de sentenças estrangeiras e a concessão de exequatur às cartas rogatórias; (Incluída pela Emenda Constitucional no 45, de 2004) [...]"
} 
atribuição ao Supremo Tribunal Federal (STF) até 2004², quando a Emenda Constitucional 45 a transferiu para o STJ. A relativamente recente transição modificou a percepção jurisprudencial sobre o tema, afetando os institutos que lhe são próprios. Registra-se, a título exemplificativo, a admissão de tutela jurisdicional de urgência no seio do processo de delibação, admitida após a transferência da competência originária para o STJ. No campo da regulamentação, ressalte-se que as normas adotadas pelo STJ, antes consubstanciadas na Resolução no 9 e posteriormente em seu Regimento Interno, receberam tratamento específico no CPC2015, nos artigos 960 a 965. Com isso, consagraram-se na legislação federal as regras que já vinham sendo usadas e reiteradas na firme jurisprudência do STJ nos últimos dez anos. ${ }^{13}$

Esta aceitação dos termos da jurisdição internacional fixada em outro país pelas regras locais pode ser descrita, por um lado, como uma pretensão a cosmopolitismo e cooperação internacional, mas também pode resultar em excessiva exposição dos jurisdicionados nacionais, que se veem submetidos a qualquer decisão estrangeira, mesmo quando inexistentes mínimos elementos de vinculação da causa com a autoridade que a proferiu ${ }^{14}$.

A discussão sobre a competência internacional, no que concerne ao requisito para homologação da decisão estrangeira, exaure-se na confirmação de que esta tenha sido proferida por autoridade competente tal como determinado em seu Estado de origem, de acordo com a dicção da LINDB ${ }^{15}$, do Regimento Interno do STJ, e finalmente do CPC2015.

A modificação da expressão juiz competente por autoridade competente, se explica porque tanto o STF quanto o STJ firmaram jurisprudência indicando que provimentos não judiciais com natureza de

12 “O sistema de delibação adotado para o reconhecimento de sentenças estrangeiras vigora no Brasil desde o Decreto n. 6.982/1878". STJ, Corte Especial, SEC 2714-AgRg,

Min. Rel. Cesar Asfor Rocha, Julgamento em: 04 de agosto de 2010.

${ }^{13}$ Sobre o tema de homologação de sentenças estrangeiras, veja-se, por todos, ARAUJO, Nadia de. Direito Internacional Privado: teoria e prática brasileira. $6^{a} \mathrm{ed}$. Porto Alegre, RS: Revolução e-book, 2016, capítulo 14.4.

${ }^{14}$ De NARDI, Marcelo. Jurisdição internacional indireta: a "autoridade competente" na homologação de sentença estrangeira no Brasil. In: Wagner Menezes (Org.). Direito Internacional em Expansão, Volume VII. Belo Horizonte, MG: Arraes Editores, 2016, p. 339 .

${ }^{15}$ Lei de Introdução das Normas de Direito Brasileiro, Decreto no 4.657/1942. A referência a juiz competente está na alínea a) do artigo 15: “Será executada no Brasil a sentença proferida no estrangeiro, que reúna os seguintes requisitos: a) haver sido proferida por juiz competente; $[\ldots]^{\prime \prime}$.

2 JOURNAL OF INSTITUTIONAL STUDIES 2 (2016) 
sentença conforme o ordenamento jurídico brasileiro também poderiam ser homologados. É o caso das decisões administrativas de divórcio provenientes do Japão, consideradas como equiparadas a decisões judiciais e homologadas ao longo do tempo tanto no STF quanto no STJ ${ }^{16}$.

O sistema brasileiro estabelece regras específicas para a jurisdição internacional, operando de forma negativa: quando há jurisdição exclusiva nacional (art. 23 do CPC2015) não se admite sentença estrangeira; quando há jurisdição concorrente (arts. 21 e 22 do CPC2015), admite-se a sentença estrangeira se não conflitar com coisa julgada internamente estabelecida; quando não há jurisdição brasileira consolidada, admite-se a sentença estrangeira. Em todos os casos de admissão, controla-se o conteúdo para preservação da ordem pública interna ${ }^{17}$.

Em poucas oportunidades as decisões de homologação de sentença estrangeira indicaram que o exame da competência da autoridade que a proferiu se projeta para investigar se houve razoáveis vínculos da causa originária com a jurisdição estrangeira ${ }^{18}$.

Uma primeira observação importante é a de que o STJ não examina a competência da autoridade estrangeira quanto a sua competência interna, ou seja, quanto à subdivisão da jurisdição no país de origem. $\mathrm{O}$ exame concernente à autoridade responsável pela sentença estrangeira se faz quanto à jurisdição do estado estrangeiro e não adentra a subdivisão interna do país ${ }^{19}$.

16 Veja-se exemplificativamente: STJ, Presidente, SE 109, Min. Rel. Sálvio de Figueiredo Teixeira, Julgamento em: 07 de março de 2005.

${ }^{17}$ RISTJ, art. 216-F. “Art. 216-F. Não será homologada a sentença estrangeira que ofender a soberania nacional, a dignidade da pessoa humana e/ou a ordem pública."

Disponível em:

$<$ http://www.stj.jus.br/publicacaoinstitucional//index.php/Regimento/article/view/532/ $\underline{3260>}$ Acesso em: 28 de janeiro de 2017.

${ }^{18}$ Vejam-se exemplificativamente: STJ, Corte Especial, SEC 2714-AgRg, Min. Rel. Cesar Asfor Rocha, Julgamento em: 04 de agosto de 2010; STJ, Corte Especial, SEC 3341, Min. Rel. Laurita Vaz, Julgamento em: 14 de junho de 2012; STJ, Corte Especial, SEC 06948AgRg, Min. Rel. Nancy Andrighi, Julgamento em: 17 de dezembro de 2012; STJ, Corte Especial, SEC 8267, Min. Rel. Ari Pargendler, Julgamento em: 20 novembro de 2013;

STJ, Corte Especial, SEC 9419, Min Rel. Maria Thereza de Assis Moura, Julgamento em: 16 de outubro de 2013; STJ, Corte Especial, SEC 12.897/EX, Min. Rel. Raul Araújo, Julgamento em: 16 de dezembro de 2015.

${ }_{19}$ STJ, Corte Especial, SE 2714/GB-AgR, Min. Rel. Cesar Asfor Rocha, Julgamento em: 04 de agosto de 2010. Na mesma linha, “[...] não interessa à ordem jurídica brasileira 
Em segundo momento, verifica-se que o STJ atua tão somente para delimitar a jurisdição exclusiva nacional, sem preocupação explícita e consistente com os vínculos que os submetidos à jurisdição estrangeira com ela teriam. Ilustrativo é o seguinte fragmento de ementa:

1. É devida a homologação de sentença estrangeira que atenda os requisitos previstos no art. 15 da Lei de Introdução às Normas do Direito Brasileiro e nos arts. 216-A a 216-N do RISTJ, bem como não ofenda a soberania nacional, a ordem pública e a dignidade da pessoa humana (LINDB, art. 17; RISTJ, art. 216-F).

2. Não há óbice à homologação da sentença estrangeira que disponha apenas sobre guarda de menor e direito à percepção de alimentos e de visitas, sem trazer à discussão imóveis situados no Brasil, por se tratar de causa de competência concorrente (CPC, art. 88), e não exclusiva, da autoridade judiciária brasileira (CPC, art. 89).

3. A competência internacional concorrente, prevista no art. 88, III, do Código de Processo Civil, não induz a litispendência, podendo a Justiça estrangeira julgar igualmente os casos a ela submetidos. Eventual concorrência entre sentença proferida pelo Judiciário brasileiro e a sentença estrangeira homologada pelo STJ, sobre a mesma questão, deve ser resolvida pela prevalência da que transitar em julgado em primeiro lugar. $[\ldots]^{20}$

Constata-se a distinção entre as sentenças estrangeiras cujo conteúdo está abrangido pela competência exclusiva da autoridade judicial brasileira (art. 23 do CPC2015), e as referenciadas no âmbito da competência concorrente (arts. 21 e 22 do CPC2015). Apenas na primeira hipótese a sentença alienígena não será passível de homologação, pois o STJ reputará incompetente a autoridade estrangeira.

O legislador brasileiro estabeleceu o limite máximo da jurisdição nacional, em matéria cível, através dos arts. 21 e 22 do CPC/2015, e fixou a reserva de jurisdição exclusiva, os casos em que não admite jurisdição estrangeira sob qualquer forma, no art. 23 do CPC/2015. Ao tomar essa decisão, elegeu critérios ou pontos de contato que constituem o expediente técnico pelo qual se examina a vinculação entre o foro e a

as divisões ou peculiaridades da competência interna dos países de origem da decisão, devendo o exame limitar-se à competência internacional ou geral". STJ, Corte Especial, SEC 4695, Min. Rel. Francisco Falcão, Julgamento em: 07 de maio de 2012. Essa era a posição jurisprudencial do Supremo Tribunal Federal. Cf, e.g.: STF, SEC 05418, Min. Rel. Maurício Corrêa, Julgamento em: 07 de outubro de 1999.

${ }^{20}$ STJ, Corte Especial, SEC 12.897/EX, Min. Rel. Raul Araújo, Julgamento em: 16 de dezembro de 2015. 
questão debatida.

Resta claro que o STJ tem por objetivo, ao examinar o requisito de autoridade estrangeira competente, tão somente verificar se não há ofensa à jurisdição exclusiva nacional.

A legislação que estabelece o parâmetro de análise do item da competência para que a sentença estrangeira possa ser reconhecida e executada no Brasil é muito sucinta, e não esclarece se esse exame deveria ser feito ou não em profundidade. Utiliza, inclusive, a palavra "competência", que na tradição brasileira porta um duplo sentido, podendo significar a divisão interna da jurisdição ou a jurisdição internacional em si mesma. Ao longo dos anos, tanto o STF quanto o STJ pouco se debruçaram sobre a questão, o que resultou numa jurisprudência em que só havia preocupação de evitar a homologação nos casos de jurisdição exclusiva dos tribunais pátrios, como se disse acima.

O envolvimento do Brasil nas discussões do Projeto de Sentenças aguça a sensibilidade para o problema do controle do exercício da jurisdição pela autoridade estrangeira em sede de homologação, o que não está claramente revelado nas decisões do STJ até o momento catalogadas. A expressiva maioria das decisões não se debruçou sobre a fixação da jurisdição estrangeira.

O ingresso do Brasil em uma futura convenção sobre circulação de sentenças pode induzir uma leitura mais restritiva do requisito legal, com exigências mais precisas de vinculação do caso concreto com a autoridade estrangeira prolatora da decisão a homologar, como o fazem muitos países estrangeiros. $\mathrm{O}$ sentido desse controle, para além de exercício da proteção da jurisdição exclusiva nacional, também é o de proteção ao jurisdicionado nacional, exigindo que a decisão estrangeira tenha sido proferida em situação na qual haja razoável envolvimento da pessoa afetada pela jurisdição estrangeira com aquele foro.

\section{A Fase de Negociações no GT}

No curso de suas reuniões, de 2012 a 2015, o Grupo de Trabalho que antecedeu a Comissão Especial era composto por especialistas dos Estados-membros da Conferência da Haia, indicados especialmente para essa tarefa. A última reunião contava com juristas participantes do projeto há mais de quinze anos, e com profissionais de larga experiência, todos dedicados ao estudo do Direito Internacional Privado. Os trabalhos foram fortemente influenciados pelas conclusões que conduziram à elaboração da Convenção sobre Eleição de Foro de 2005, conforme 
declarado nos relatórios finais das reuniões ${ }^{21}$.

A mescla de experiências e culturas jurídicas constituiu a riqueza do trabalho, ao mesmo tempo em que revelou a imensa dificuldade de se avançar para um anteprojeto de Convenção. À mesa de discussões do Grupo de Trabalho estiveram representados África do Sul, Alemanha, Argentina, Austrália, Bielorrúsia, Brasil, Canadá, China, Chipre, Coreia do Sul, Costa Rica, Espanha, Estados Unidos da América, Inglaterra, México, Rússia, Sérvia, Singapura, Suíça, e União Europeia, o que bem ilustra o quão diferentes são os sistemas jurídicos envolvidos e suas respectivas restrições à circulação de sentenças. A forma de tratamento da imunidade dos Estados estrangeiros nas jurisdições nacionais (principalmente no que se refere a posições de imunidade absoluta e imunidade relativa), o reconhecimento de decisões sem conteúdo monetário direto, e as restrições ao reconhecimento de julgamentos sobre indenização de danos extrapatrimoniais são algumas das muitas divergências usuais entre os sistemas da common law e da civil law.

O Brasil evoluiu de uma posição preponderantemente de observador nas primeiras reuniões para de ativo colaborador, não se furtando de formular contribuições de natureza técnica ou de relatar a experiência nacional sobre a matéria. Os temas em que o Brasil atuou com intensidade foram os de proteção à imunidade de Estado, de respeito à jurisdição exclusiva, e de proteção ao consumidor e ao trabalhador. ${ }^{22}$

As discussões no âmbito do Grupo de Trabalho evoluíram para uma minuta de convenção, que foi utilizada como base para as discussões da Comissão Especial de 2016. O objetivo do anteprojeto foi o de favorecer e simplificar a circulação internacional de sentenças, e com isso contribuir para o desenvolvimento econômico e social global. Do ponto de vista brasileiro, espera-se um considerável aumento da circulação de sentenças para o exterior, mais equilibrado com a conhecida abertura do Brasil para as sentenças estrangeiras, sem maiores controles da jurisdição exercida em outro país, salvo no que se refere à proteção da ordem pública nacional e da jurisdição exclusiva. A participação nos trabalhos enseja

${ }^{21}$ Os relatórios podem ser consultados na página pública da Conferência da Haia de Direito Internacional privado. Disponível em:

$<$ https://www.hcch.net/en/projects/legislative-projects/judgments/recent-

developments $>$. Acesso em: 21 de novembro de 2016.

${ }^{22}$ Marcelo De Nardi participou das $2^{\mathrm{a}}$ a $5^{\mathrm{a}}$ reuniões do Grupo de Trabalho, por indicação do Governo Brasileiro, preparou manifestações técnicas de avaliação e sugestões no período, além de ter comparecido junto com Nadia de Araujo a vários eventos realizados no Brasil a respeito do tema. Para a primeira reunião da Comissão Especial preparou um documento informativo sobre proteção ao consumidor.

2 JOURNAL OF INSTITUTIONAL STUDIES 2 (2016) 
ainda uma investigação acadêmica especializada, que poderá informar adequadamente uma decisão do governo brasileiro quanto à conveniência de se ratificar a convenção que virá.

\section{A Comissão EsPecial E OS Principais Pontos DiscuTIDOS}

Como consideração geral é preciso apontar que o anteprojeto evidencia a definição de alguns conceitos resultantes das negociações dos últimos quatro anos. O modelo proposto é de uma convenção vinculante, que passaria a integrar a legislação interna dos países membros, em oposição à adoção de princípios e regras de soft law. Com isso, atingir-seia o objetivo de promover a harmonização das soluções de Direito Internacional Privado. Por outro lado, o foco é estabelecer apenas regras para o reconhecimento e execução de decisões estrangeiras, o que configura uma convenção do tipo simples, pois não há pretensão de estabelecer também regras para a definição da jurisdição interna dos países, o que foi tentado na iniciativa dos anos noventa, quando se pretendia realizar uma convenção dupla.

A convenção guardará, na medida do possível, coerência com a Convenção sobre Eleição de Foro de 2005. Também se procurará observar as disposições pertinentes constantes de outras convenções concluídas no âmbito da Conferencia da Haia, como a Convenção sobre a Cobrança Internacional de Alimentos para Crianças e Outros Membros da Família, de 23 de novembro de 2007, atualmente em vias de aprovação no Congresso Nacional.

O objetivo final é garantir maior segurança jurídica na circulação internacional de decisões judiciais civis e comerciais. Com isso, evita-se a duplicação de procedimentos em Estados diversos e diminuem-se os custos das transações e as despesas judiciais. Promove-se, ainda, maior previsibilidade quanto à circulação de decisões judiciais, auxiliando as partes em suas decisões de caráter comercial.

\section{O Anteprojeto: análise de certos aspectos}

O anteprojeto foi dividido em dois capítulos: âmbito de aplicação e reconhecimento e execução, contendo, ao todo, quinze artigos. Nesse texto não estão contidas as previsões instrumentais, como regras de 
adesão, depósito, comunicações entre as partes, dentre outras. Também não estão presentes elementos autorizadores de reservas, o que já se vislumbra deva se apresentar na próxima reunião da Comissão Especial.

O capítulo relativo ao âmbito de aplicação começa pela definição do escopo, seguido pela lista de matérias fora do âmbito da convenção, e termina com as definições aplicáveis.

A polêmica se inicia com as divergências sobre a definição do que sejam "questões civis e comerciais", a grande delimitação de escopo da convenção, que aparece já no primeiro artigo. A terminologia, empregada pela Conferência da Haia em outros documentos, foi objeto de grande discussão. Divergiram os Estados acerca da necessidade ou não de se incluir uma definição mais precisa no anteprojeto. Exemplo da divergência entre os sistemas jurídicos de common law e de direito civil, esse tema deve ser objeto de maiores investigações.

Quanto às matérias excluídas do anteprojeto, houve discussão a respeito de transporte aéreo. O Brasil vislumbra possibilidade de apresentar proposta de inclusão dessa hipótese no regime da futura convenção, em conjunto com o GRULAC ${ }^{23}$ e com os BRICS ${ }^{24}$.

A definição de consumidor também mereceu discussão acalorada, havendo divergência entre a definição restritiva, já adotada pela Convenção sobre Eleição de Foro de 2005, e aquela pretendida por alguns países. Esse tópico será aprofundado na próxima reunião, e qualquer pretensão de modificação dependerá do convencimento de outros participantes. De todo modo, o tratamento dado ao tema na nova versão do anteprojeto, que é de difícil consenso internacional, já reflete um avanço. "Consumidor" ficou definido a partir de uma visão clássica contratual, limitada a atividades domésticas, mas permitindo que as sentenças proferidas a seu favor circulem internacionalmente no regime da futura convenção. A solução encontrada para proteção do consumidor foi de limitar a circulação das sentenças contra ele proferidas aos casos em que a jurisdição for exercida no seu domicílio, ou ele tenha se submetido expressamente à jurisdição estrangeira.

No exame do artigo $4^{\circ}$ do segundo capítulo, sobre questões gerais, um dos pontos polêmicos foi a proposta de remoção da regra segundo a qual o tribunal do Estado requerido não faria revisão sobre os fatos já decididos pelo tribunal do Estado requerente; o tema ficou para ser revisitado na segunda reunião. É um tópico sensível, porque a regra geral na maioria dos países, especialmente nos de direito civil, é a de que em

23 "Grupo da Latino-américa e Caribe", reunião informal dos países dessa região em foros internacionais.

${ }^{24}$ Brasil, Rússia, Índia, China, e África do Sul.

2 JOURNAL OF INSTITUTIONAL STUDIES 2 (2016) 
casos de reconhecimento não se revê o mérito da decisão objeto de reconhecimento, senão para análise de violação da ordem pública, segundo o sistema de delibação. Ainda no artigo 4.4, deixou-se para a próxima reunião a definição sobre a possibilidade de negar o pedido de reconhecimento quando ainda pendente de recurso à sentença sujeita à circulação.

\section{Bases Indiretas de Jurisdição}

A importância de examinar, ou pelo menos compreender, a atividade de controle indireto da jurisdição internacional aparece na evolução do já mencionado Judgments Project da Conferência da Haia de Direito Internacional Privado. $\mathrm{O}$ relato das origens do projeto no relatório explicativo da Convenção sobre Eleição de Foro de 2005 pressupõe o controle indireto dos fundamentos da jurisdição exercida no estrangeiro como ponto de convergência de certos fundamentos comuns para exercício de jurisdição, que quando exercidos sob essa forma resultariam em circulação facilitada sob o regime da convenção sugerida.

A evolução desses conceitos, com as dificuldades a eles inerentes ${ }^{25}$, resultou em anteprojeto de convenção que arrola alguns fundamentos reconhecidos como autorizadores de circulação sob o regime da convenção (white list, approved grounds for jurisdiction), que podem ser não exaustivamente resumidos $\mathrm{em}^{26}$ :

${ }^{25}$ HARTLEY, Trevor; DOGAUCHI, Masato. Convention of 30 June 2005 on choice of court agreements: explanatory report. Haia: Secretariado Permanente da Conferência Scheveningseweg 6, 2005, p. 785. Disponível em:

$<$ https://assets.hcch.net/docs/a90b5aea-89cf-4541-b7b7-e5e960703845.pdf $>$. Acesso em: 03 de janeiro de 2017: [...] it became apparent as work proceeded that it would not be possible to draw up a satisfactory text for a "mixed" convention within a reasonable period of time. The reasons for this included the wide differences in the existing rules of jurisdiction in different States and the unforeseeable effects of technological developments, including the Internet, on the jurisdictional rules that might be laid down in the Convention. [...]

${ }^{26}$ COMISSÃO ESPECIAL SOBRE RECONHECIMENTO E EXECUÇÃO DE SENTENÇAS ESTRANGEIRAS. 2016 Preliminary Draft Convention. Haia: Conferência da Haia sobre Direito Internacional Privado, 2016. Disponível em: $<$ https://assets.hcch.net/docs/42a96b27-11fa-49f9-8e48-a82245aff1a6.pdf $>$. Acesso em: 30 de agosto de 2016. 
a) domicílio (habitual residence) da pessoa natural - art. 5.1(a);

b) manutenção de filial, agência ou estabelecimento pela pessoa jurídica - art. 5.1(d);

c) submissão à jurisdição - art. 5.1(c, e e f);

d) local do cumprimento da obrigação contratual - art. 5.1(g); e

e) local da prática do ato danoso - art. 5.1(j).

O domínio desses conceitos, será essencial para aperfeiçoar os critérios de admissão de eficácia de sentenças estrangeiras no Brasil, especificando o exame indireto da jurisdição internacional da autoridade estrangeira. Caso o Brasil resolva se engajar em uma futura convenção sobre circulação de sentenças estrangeiras como proposto no Judgments Project, o exame das condições de jurisdição deverá ser aprofundado, e as sentenças brasileiras que tiverem prospectiva eficácia no estrangeiro deverão expressar as razões pelas quais a jurisdição nacional foi admitida, como forma de facilitar o ajuste às regras de circulação.

$\mathrm{Na}$ versão final das negociações constata-se que o artigo $5^{\circ}$, que trata do conceito de bases indiretas de jurisdição ${ }^{27}$, ou filtros jurisdicionais, é, sem dúvida, o mais extenso e complexo da convenção. Foi a solução encontrada para viabilizar a convenção, ante a ausência nos Estados partícipes da negociação de um sistema uniforme de definição da jurisdição, ou seja, de regras uniformes de jurisdição direta. Os filtros jurisdicionais são limites impostos ao reconhecimento e execução com o qual os Estados estão de acordo, sendo interpretados como as hipóteses em que os Estados que receberão a sentença estrangeira para reconhecimento e execução, aceitando como legítimo o exercício da jurisdição por uma Corte que não seja sua. Por outro lado, os filtros jurisdicionais aumentam o escrutínio sobre a vinculação com o caso concreto da jurisdição do Estado requerente.

Esse trecho da convenção é de substancial relevância, pois as previsões representam um conjunto de regras que permite aos Estados se

${ }^{27}$ Entende-se por jurisdição internacional indireta, ou mais precisamente declarando o conteúdo aqui pretendido examinar, o controle indireto da jurisdição internacional, a ação de determinado Estado, em momento de examinar as condições para que se gerem efeitos de sentença estrangeira em seu ambiente de influência política, de verificar se o exercício da jurisdição pelo juízo de origem se deu em condições de razoável vinculação àquele foro. Cf. De NARDI, Marcelo. Jurisdição internacional indireta: a "autoridade competente" na homologação de sentença estrangeira no Brasil. In: Wagner Menezes (Org.). Direito Internacional em Expansão, Volume VII. Belo Horizonte, MG: Arraes Editores, 2016, p. 335-336.

2 JOURNAL OF INSTITUTIONAL STUDIES 2 (2016) 
obrigarem confiando na lisura e qualidade do exercício de jurisdição pelos demais. Foi, portanto, matéria de intensas discussão e divergências, ainda não completamente solucionadas. Muitas das emendas a serem discutidas na próxima reunião foram apostas nesse artigo e seus incisos.

A técnica interpretativa, aplicável ao artigo $5^{\circ}$ é a de que a Convenção prevê uma lista exaustiva de bases de jurisdição aceitas, situação cuja ocorrência estabelecerá a obrigação do Estado parte destinatário do pedido de reconhecimento e execução de admitir a sentença estrangeira que tenha sido proferida nessas condições. Ausente alguma das bases previstas na convenção no caso concreto, o Estado parte a que dirigido o pedido de reconhecimento e execução poderá recusá-la.

O fato principal que induz vinculação suficiente à jurisdição, ou seja, que estabelece base para reconhecimento do exercício da jurisdição estrangeria, é a residência habitual do réu no local do foro. Nessas condições, partindo de um modelo simples de processo que supõe um autor e um réu, tem-se mundialmente reconhecido como razoável o exercício de poder jurisdicional sobre o réu domiciliado no país que é a sede da autoridade jurisdicional, o que facilita sobremaneira sua defesa. Consolidação desse princípio está no artigo 5.1. $a^{28}$.

$\mathrm{Na}$ visada do autor, daquele que propôs o processo, a submissão expressa à jurisdição do foro a que recorreu revela suficiente vinculação para os casos em que ele venha a ser derrotado e condenado pelo juízo estrangeiro. $O$ efeito também se estabelece se o réu consentir expressamente com a jurisdição. O princípio da submissão está contido nas alíneas $c$ e $e$ do artigo 5.129. Está ainda em discussão uma hipótese de submissão tácita, que ocorreria quando o réu se apresenta perante o juízo e contesta o pedido sem discutir a jurisdição, desde que essa impugnação seja admissível (artigo 5.1.f).

As bases de jurisdição aceitas com relação a pessoa jurídica, quando

28 "Article 5 - Bases for recognition and enforcement; 1 . A judgment is eligible for recognition and enforcement if one of the following requirements is met -; a) the person against whom recognition or enforcement is sought was habitually resident in the State of origin at the time that person became a party to the proceedings in the court of origin; $[\ldots]^{\prime \prime}$

29 "Article 5 - Bases for recognition and enforcement; 1 . A judgment is eligible for recognition and enforcement if one of the following requirements is met $-[\ldots]$; c) the person against whom recognition or enforcement is sought is the person that brought the claim on which the judgment is based; [...] e) the defendant expressly consented to the jurisdiction of the court of origin in the course of the proceedings in which the judgment was given; $[\ldots]^{\prime \prime}$. 
ela for a autora, são equivalentes às da pessoa física, sobrelevando o princípio da submissão. Já quando a pessoa jurídica for a ré, o princípio da residência habitual se aplica, naturalmente com as dificuldades de se estabelecer qual é o local da nacionalidade da pessoa jurídica, que pode ser o local da sua constituição ${ }^{30}$, o local da sede da administração, ou outros elementos semelhantes. Embora a interpretação não esteja declarada, o relatório explicativo conterá declaração nesse sentido.

Também se admite satisfatória vinculação para fins jurisdicionais quando houver no foro filial, agência, ou outro estabelecimento sem personalidade destacada da pessoa que a constituiu, desde que o objeto do processo esteja relacionado às atividades praticadas por esse ente subsidiário (artigo 5.1.d).

Na matéria contratual a regra de reconhecimento de jurisdição segue caminho semelhante ao do inc. II do art. 21 do CPC2015 ${ }^{31}$, embora com restrições maiores. A limitação está relacionada à evolução da jurisprudência norteamericana e canadense, que não reconhece jurisdição adequada quando o réu que foi parte do contrato não dirigiu suas atividades propositalmente e substancialmente para produzir efeitos jurídicos no Estado do foro. A expressão adotada no artigo 5.1.g para instrumentalizar a exceção é: "the defendant's activities in relation to the transaction clearly did not constitute a purposeful and substantial connection to that State."

\section{Bases Exclusivas de Jurisdição e Causas de Recusa de Reconhecimento}

$\mathrm{O}$ artigo $6^{\mathbf{0}}$ cuida das bases exclusivas de jurisdição, cujas regras se superpõem às do artigo $5^{\circ}$, estabelecendo a obrigação dos membros da convenção de reconhecer qualquer sentença proferida segundo seus termos. A leitura mais aprofundada desse dispositivo revela que está a traduzir, de forma negativa, uma harmonização das normas sobre jurisdição, iniciando, pois, a uniformização da jurisdição direta: os Estados que aderirem à futura convenção concordarão que para os assuntos tratados no artigo $6^{\circ}$ as únicas bases jurisdicionais aceitáveis são as lá declaradas.

$\mathrm{O}$ artigo $7^{\circ}$ trata das causas para recusa de reconhecimento e execução.

${ }^{30}$ Como é a opção brasileira, art. 11 da LINDB.

31 "Art. 21. Compete à autoridade judiciária brasileira processar e julgar as ações em que: $[\ldots]$; II - no Brasil tiver de ser cumprida a obrigação; [...]". 
São os requisitos formais já conhecidos, além da cláusula de ordem pública. A redação usa o termo "manifestamente" para dar uma qualificação maior à exceção, no mesmo sentido, aliás, da Convenção Interamericana sobre Normas Gerais de Direito Internacional Privado, concluída em Montevidéu, Uruguai, em 8 de maio de 1979, e internalizada no Brasil pelo Decreto no 1.979, de 9 de agosto de 1996.

De destacar que ainda não foram discutidas as questões que poderão ser objeto de reservas ou declarações especiais, o que certamente permitirá ajustar o anteprojeto às necessidades de um número maior de Estados no futuro.

Ao final da reunião, muitos Estados reservaram sua posição com relação a diversos pontos, ante a necessidade de articulação a respeito no plano interno e ainda com outros Estados. Os participantes foram estimulados a desenvolver debates em contatos e reuniões antes da próxima reunião da Comissão Especial, inclusive à distância.

\section{QUESTIONÁRIO SOBRE TEMAS DE INTERESSE DO BRASIL}

\section{As Perguntas}

O Brasil participou desde o início da segunda fase do Projeto de Sentenças e tem interesse em engajar-se na futura convenção, já que as sentenças brasileiras, em função das regras de controle indireto de jurisdição presentes na legislação interna de diversos Estados, podem encontrar resistência para o seu reconhecimento e execução no exterior. No fluxo reverso, o atual sistema brasileiro de reconhecimento e execução de sentenças estrangeiras, consubstanciado nas regras dos artigos 960 a 965 do CPC2015, permite a homologação da sentença estrangeira sem opor maiores restrições à forma em que definida a jurisdição estrangeira ${ }^{32}$.

Considerando a estrutura jurídica brasileira sobre a matéria, e observando os interesses peculiares do Brasil, há alguns temas que devem ser adequadamente examinados e melhor estudados pelo país para

\footnotetext{
32 Veja-se que de acordo com o inciso I do artigo 963 do CPC2015, o requisito é de que "a decisão tenha sido proferida por autoridade competente". A jurisprudência consolidada do STJ entende que esse conceito deve ser definido pela autoridade prolatora. A impossibilidade de homologação se dá somente quando se trata de hipótese de competência exclusiva da autoridade brasileira, nas três situações do artigo 23 do CPC2015 (correspondente ao artigo 89 do CPC1973).
} 
embasar sua posição na próxima fase das negociações. Esses temas são: o escopo da definição da expressão "questões civis e comerciais", visando compreender os limites da futura convenção conforme a posição operacional brasileira (i); a definição de consumidor, considerando que no momento a proteção outorgada pelo Brasil aos consumidores é maior do que a oferecida no anteprojeto (ii); os aspectos polêmicos acerca dos filtros indiretos de jurisdição, estrutura jurídica pouco desenvolvida no Brasil, e cuja exigência não faz parte da prática de reconhecimento e execução de sentenças estrangeiras neste país (iii); e questões relativas à jurisdição exclusiva, como forma de proteção às decisões soberanas do Estado brasileiro de assegurar certos interesses, como declarados no artigo 23 do CPC2015 (iv).

Para se ter uma ideia mais precisa da posição da sociedade civil a respeito desses temas, o Grupo de Pesquisa "Direito Internacional Privado no Brasil e nos Foros Internacionais" (DGP CNPq), numa colaboração da PUC-Rio, UFMG e Unisinos, ${ }^{33}$ elaborou um questionário e realizou uma consulta à diversos operadores de direito especializados, para poder auxiliar na melhor compreensão dos efeitos do projeto de convenção para o direito nacional.

O questionário centrou-se na análise de duas questões relativas ao escopo da convenção e ainda dois pontos do Anteprojeto que são importantes para o país: a determinação do escopo de proteção dos consumidores e trabalhadores; e as regras que impactam a proteção da propriedade intelectual, em especial daquelas situações em que um determinado direito é considerado registrável em um país, mas não em outro (artigo $5^{\circ}$ e artigo $6^{\circ}$ ).

A primeira pergunta procurava compreender qual o escopo da convenção, uma vez que no anteprojeto constava como relacionado à "questões civis e comerciais", sem apresentar uma definição a respeito do significado a expressão. Assim, queria-se saber qual o alcance da expressão em relação ao direito brasileiro.

A segunda pergunta procurava saber se a exclusão do escopo do tema de transporte de passageiros e mercadorias deveria ser mantida ou se havia interesse em incluir esse tema no escopo da convenção.

Com relação à proteção ao consumidor, levando em conta que o anteprojeto apresentava um sistema cuja proteção parecia estar em

${ }^{33}$ O questionário foi elaborado pelos Profs. Nadia de Araujo, Fabricio Polido e Marcelo De Nardi. Foi enviado a um grupo selecionado por sua experiência, entre os meses de setembro a novembro de 2016. A metodologia empregada não teve a pretensão de ter senão algumas opiniões abalizadas, sendo de caráter qualitativo e não quantitativo. Todas as respostas estão disponíveis para os integrantes do Grupo de Pesquisa. 
patamares inferiores ao que se pratica no Brasil, queria-se saber se haveria valor em instituir um sistema facilitado de circulação de sentenças a favor do consumidor, e admitir um sistema limitado de circulação internacional de sentenças contra o consumidor, além dos riscos associados a essa solução.

No que toca o tema da Propriedade Intelectual, procurava-se entender se as diferenças de tratamento entre a possibilidade de serem certos direitos registráveis ou não, a partir das definições do direito interno de cada país, seriam impactados pela possibilidade de circulação internacional de sentenças em matéria de propriedade intelectual.

A temática surge em dois blocos de dispositivos - referentes às bases de reconhecimento e execução e bases de jurisdição exclusiva do Estado prolator das decisões judiciais, que deve ser respeitada pelos Estados do reconhecimento/execução:

(1) a territorialidade inerente a esses direitos; e

(2) a adoção pelo Projeto de definição baseada na diferença entre direitos registráveis (depositáveis) e não registráveis.

A minuta vigente adotou o critério de arrolar certos tipos internacionalmente comuns de propriedade intelectual, classificando-os entre registráveis e não registráveis para induzir certas consequências sutilmente diversas.

A problemática se apresentou no artigo 5, relativo às bases indiretas de jurisdição (artigo 5.1, itens $k$ e $l$ ) e no artigo $6^{\circ}$, relativo às bases exclusivas de jurisdição (artigo $6, a){ }^{34}$

34 “Article 5 - Bases for recognition and enforcement: 1. A judgment is eligible for recognition and enforcement if one of the following requirements is met $-[\ldots] \mathrm{k}$ ) the judgment ruled on an infringement of a patent, trademark, design, [plant breeders' right,] or other similar right required to be [deposited or] registered and it was given by a court in the State in which the [deposit or] registration of the right concerned has taken place, or is deemed to have taken place under the terms of an international or regional instrument; Article 6 Exclusive bases for recognition and enforcement: Notwithstanding Article 5-a) a judgment that ruled on the registration or validity of patents, trademarks, designs[, plant breeders' rights,] or other similar rights required to be [deposited or] registered shall be recognised and enforced if and only if the State of origin is the State in which [deposit or] registration has been applied for, has taken place, or is deemed to have been applied for or to have taken place under the terms of an international or regional instrument; $[\ldots]$ ". 
Com relação ao artigo 5.1, $k$, havia duas perguntas. Na primeira sobre quais as consequências possíveis para o Brasil, tanto ativa quanto passivamente, quanto à inclusão da cláusula de direitos de obtentores de variedades vegetais - plant breeder's right? E na segunda, se a territorialidade dos direitos de propriedade intelectual ficaria efetivamente protegida pela aplicação deste dispositivo, e em que medida.

Já para o item $l$, do artigo 5.1, queria-se saber se a territorialidade dos direitos de propriedade intelectual ficariam efetivamente protegida pela aplicação deste dispositivo e em que medida.

Finalmente, com relação ao artigo $6, a^{35}$, se a previsão seria suficiente para garantir a territorialidade, e quais as consequências possíveis para o Brasil, tanto ativa quanto passivamente, quanto à inclusão da cláusula de direitos de obtentores de variedades vegetais - plant breeder's right.

\section{As Respostas}

O Grupo de Pesquisa sensibilizou a comunidade especializada brasileira para o questionário, que foi respondido por advogados, juízes estaduais e federais, ministério público, defensoria da união e advogados da união, além de diversos operadores que são também professores, e professores especializados em direito internacional privado.

O rico material obtido está sendo analisado e será vertido em um relatório para auxiliar a formulação da posição brasileira para a reunião de fevereiro de 2017. Nesse primeiro momento, em dezembro de 2016, o Grupo de Pesquisa se debruçou somente sobre a primeira parte do questionário, e em especial sobre o âmbito de aplicação da convenção, que será objeto da analise abaixo. Desta forma, por ora, esta manifestação discutirá somente o âmbito de aplicação da convenção, no que diz respeito a extensão da expressão questões cíveis e comerciais, para verificar se o texto do anteprojeto está em condições de ser adotado pelo Brasil no curso das negociações. Por isso, não serão ainda comentadas as demais perguntas da parte I, nem a parte II do questionário, que tratou das

35 "Article 6 Exclusive bases for recognition and enforcement: Notwithstanding Article $5-$ a) a judgment that ruled on the registration or validity of patents, trademarks, designs[, plant breeders' rights,] or other similar rights required to be [deposited or] registered shall be recognised and enforced if and only if the State of origin is the State in which [deposit or] registration has been applied for, has taken place, or is deemed to have been applied for or to have taken place under the terms of an international or regional instrument; $[\ldots]^{\prime \prime}$. 
questões relativas à propriedade intelectual.

\section{ESCOPO DO ANTEPROJETO DE CONVENÇÃO: O QUE SÃO “Questões Cíveis e CoMerciais"?}

O anteprojeto estabelece no artigo $1^{o}$ que o âmbito de aplicação da convenção será para o reconhecimento e execução de sentenças relativas às questões cíveis e comerciais, excluindo, desde logo, temas sobre questões de aduana, tributos e administrativo.

A matéria do âmbito de aplicação do anteprojeto e por consequência do que significa a expressão "questões cíveis e comerciais" esteve em debate antes mesmo do início dos trabalhos da Comissão Especial, e foi objeto de documento de trabalho do Secretariado da Conferência da Haia, apresentado antes do início da reunião de junho de 2016. ${ }^{36}$ Naquele estudo, o Secretariado informa que a expressão foi utilizada como regra para o âmbito de aplicação da Convenção da Haia sobre eleição de foro, finalizada em 2005, e que entrou em vigor em $2015^{37}$. Desde o início do Projeto que resultou no presente anteprojeto, o Secretariado e os Estados reconheceram que o futuro instrumento deveria ter forte identidade com a convenção referida.

O teor da expressão é esclarecido no documento de trabalho acima citado, baseado no Relatório Explicativo da Convenção sobre Eleição de Foro de 2005, elaborado pelos professores Trevor Hartley e Masato Dogauchi ${ }^{38}$. No parágrafo 49 o Relatório elucida o teor da expressão, que esclarece ter o objetivo de estabelecer um conceito que signifique uma interpretação autônoma ${ }^{39}$. A razão dessa preocupação é distinguir os

\footnotetext{
${ }^{36}$ Veja-se Information doc. N. 4 de junho de 2016.

${ }^{37}$ Para o texto e maiores informações, veja-se em: $<$ www.hcch.net/pt/instruments/conventions/specialised-sections/choice-of-court $>$. O Brasil ainda não aderiu a essa convenção.

${ }^{38}$ Para a versão oficial do Relatório, bem como tradução em outras línguas, veja-se em <https://www.hcch.net/pt/publications-and-studies/details4/?pid=3959>. Acesso em: 03 de janeiro de 2017.

${ }^{39}$ HARTLEY, Trevor; DOGAUCHI, Masato. Convention of 30 June 2005 on choice of court agreements: explanatory report. Haia: Secretariado Permanente da Conferência Scheveningseweg 6, 2005, p. 41. Disponível em: $<$ https://assets.hcch.net/docs/a90b5aea89cf-4541-b7b7-e5e960703845.pdf>. Acesso em: 03 de janeiro de 2017. "49. Civil or commercial matters. Like other concepts used in the Convention, "civil or commercial
} 
direitos patrimoniais disponíveis, que são da esfera do direito privado, dos direitos indisponíveis e do direito público.

Ao final dos debates da $1^{\text {a }}$ reunião da Comissão Especial, o Aidemémoire (Working Document n. 70 da Comissão Especial) apontou como elemento para continuação dos debates a preocupação com a expressão, em relação às sentenças que imponham a responsabilidade do Estado.

Para iniciar a análise das respostas brasileiras é preciso esclarecer que, quando se está discutindo o sentido de uma convenção internacional cujo objetivo é uniformizar as regras de reconhecimento e execução de sentenças estrangeiras, o princípio que prevalece é o da interpretação autônoma, destacado de um sistema nacional ou internacional em particular.

As posições dos juristas brasileiros e a interpretação por eles adotada, portanto, não deve interferir na compreensão do conceito de "matéria cível e comercial" para os efeitos da futura convenção quando for internalizada no país: seu conteúdo deve ser capturado a partir do sentido decorrente da operação da própria convenção. Nesse passo, parece claro para os juristas brasileiros ser este o caminho correto a seguir, pois houve manifestações no sentido de que a qualificação da expressão deve ser extraída do próprio documento.

Neste momento de preparação da posição brasileira, para atuação na próxima reunião da Comissão Especial, a intenção do Grupo de Pesquisa foi ouvir a sociedade civil por seus especialistas, para verificar se o conceito de matéria cível e comercial pode ser considerado compatível com o ordenamento jurídico nacional e não ofende a ordem pública interna. Desta forma, finalizada a convenção estará o estado brasileiro em posição de a ela aderir.

Ainda das respostas recebidas, verificou-se consenso quanto a não estar incluída no conceito acima matéria criminal e de direito público, no sentido de que a matéria cível tem uma definição residual, ou seja, o que não é especificado para outras áreas do direito. No entanto, constatou-se

matters" has an autonomous meaning: it does not entail a reference to national law or other instruments. The limitation to civil or commercial matters is common in international conventions of this kind. It is primarily intended to exclude public law and criminal law. The reason for using the word "commercial" as well as "civil" is that in some legal systems "civil" and "commercial" are regarded as separate and mutually exclusive categories. The use of both terms is helpful for those legal systems. It does no harm with regard to systems in which commercial proceedings are a sub-category of civil proceedings. However, certain matters that clearly fall within the class of civil or commercial matters are nevertheless excluded from the scope of the Convention under Article 2."

2 JOURNAL OF INSTITUTIONAL STUDIES 2 (2016) 
em algumas respostas a preocupação com a necessidade de excluir do escopo da convenção qualquer possibilidade de responsabilização do Estado brasileiro. De ressaltar que esse tema aflige também outros Estados e foi expressamente abordado no Artigo 2, números 4 e $5^{40}$, além de constar entre os temas apontados para serem objeto da próxima reunião, conforme registro no Aide-Mémoire ${ }^{41}$.

Em sua conclusão, o Grupo de Pesquisa constatou que a expressão "questões civis e comerciais" está adequada ao que correntemente entendem os juristas brasileiros, e por essa razão a posição brasileira pode ser no sentido de apoiar o texto atualmente em negociação.

\section{CONCLUSÃO}

Finalizada a primeira rodada de negociações, pode-se afirmar que os objetivos do Projeto de Sentenças restaram contemplados no anteprojeto.

40 "Article 2 Exclusions from scope: 1. This Convention shall not apply to the following matters $-[\ldots]$ 4. A judgment is not excluded from the scope of this Convention by the mere fact that a State, including a government, a governmental agency or any person acting for a State, was a party to the proceedings. 5. Nothing in this Convention shall affect privileges and immunities of States or of international organizations, in respect of themselves and of their property."

${ }^{41}$ Veja-se o trecho pertinente do Aide-Mémoire de 8 de junho de 2016. "Items identified for further consideration As noted above, the draft Convention will be further discussed at the next meeting of the Special Commission. Delegations foreshadowed the need for further work, and further discussion, in relation to a number of topics. Some specific issues were identified as requiring further consideration in the course of preparation for the next meeting of the Special Commission, including the following: The concept of "civil or commercial matters" requires further discussion and clarification. In particular, further consideration is needed as to the extent to which the proposed Convention should apply to claims brought by a government agency or public authority on behalf of affected parties to claim compensation for harm suffered, whether in conjunction with other enforcement action or separately. The application of the draft Convention to the liability of States for acts or omissions in the exercise of state authority was also discussed. The possibility of expressly excluding such matters from scope by appropriate language in Art 1 and/or Art 2(5) of the draft Convention, or through a declaration mechanism, will be considered at a future meeting of the Special Commission. This issue is closely linked to the question of what is meant by "civil or commercial matters". 
O êxito da reunião se constata da significativa aprovação pelos participantes da estrutura geral e de muitas das especificidades propostas pelo Grupo de Trabalho que antecedeu a Comissão Especial, especialmente no que diz respeito às regras sobre as bases indiretas de jurisdição.

De uma perspectiva histórica, informada pelas dificuldades que o próprio Projeto de Sentenças enfrentou em sua evolução, fica evidente o avanço das negociações, e já se percebe a evolução na posição dos Estados, que estabeleceram ao longo do tempo a confiança mútua necessária para admissão em território próprio da sentença proferida em Estado estrangeiro, sem muitas restrições. A percepção de que tal admissão implicaria renúncia a uma parcela de sua soberania convertese em reafirmação dessa, em nome de maior civilidade e do respeito às relações entre os Estados.

Os trabalhos da primeira reunião são resultado de um movimento de aproximação de expectativas e necessidades, notando-se a construção de pontes de conexão entre os diversos países participantes, dispostos a cooperar para a realização da atividade jurisdicional em uma perspectiva transfronteiriça.

Da analise do Grupo de Pesquisa dos pontos controversos, a solução encontrada para o primeiro deles, que diz respeito ao alcance do âmbito de aplicação da convenção para questões cíveis e comerciais, mostra-se em condições de ser aceita pelos negociadores brasileiros. Nesse sentido, as respostas a essa pergunta no questionário enviado aos juristas brasileiros, evidenciou que sua adoção não trará inconveniente ao entendimento atual sobre o seu escopo, pelo que deve ser alvo do apoio do Brasil nas negociações.

O Brasil, como participante ativo das negociações, e eventual aderente à futura convenção, está diante de uma boa oportunidade para um aggiornamento de sua posição sobre as sentenças com circulação internacional. A questão se apresenta bifacetada: em perspectiva ativa, quando a sentença brasileira deva ser executada no exterior, a futura convenção oferecerá um ambiente propício para o seu reconhecimento e execução, uma vez que se saberá de antemão quais as regras uniformes aplicáveis para o controle indireto de jurisdição. Em perspectiva passiva, concernente às sentenças provenientes do exterior, a adesão à futura convenção induzirá uma crítica à atual interpretação do requisito da autoridade competente, ensejando um repensar da atual abertura brasileira às sentenças estrangeiras. 


\section{REFERÊNCIAS}

ARAUJO, Nadia de (Org.). Cooperação jurídica internacional no Superior Tribunal de Justiça: Comentários à Resolução no 9/2005. Rio de Janeiro, RJ: Renovar, 2010.

ARAUJO, Nadia de. Direito Internacional Privado: teoria e prática brasileira. 6ª ed. Porto Alegre, RS: Revolução eBook, 2016.

BELL, Avi. Libel tourism: international forum shopping for

defamation claims. Jerusalém: Jerusalem Center for Public Affairs, 2008. Disponível em: $<$ http://jcpa.org/wpcontent/uploads/2011/09/libeltourism.pdf $>$. Acesso em: 24 de abril de 2016.

CASTRO, Amilcar. Direito Internacional Privado. $5^{\underline{a}}$ e. Rio de Janeiro, RJ: Forense, 1995.

COMISSÃO ESPECIAL SOBRE RECONHECIMENTO E EXECUÇÃO DE SENTENÇAS ESTRANGEIRAS. 2016 Preliminary Draft

Convention. Haia: Conferência da Haia sobre Direito Internacional Privado, 2016. Disponível em: $<$ https://assets.hcch.net/docs/42a96b2711fa-49f9-8e48-a82245aff1a6.pdf $>$. Acesso em: 30 de agosto de 2016.

De NARDI, Marcelo. Jurisdição internacional indireta: a "autoridade competente" na homologação de sentença estrangeira no Brasil. In: Wagner Menezes (Org.). Direito Internacional em Expansão, Volume VII. Belo Horizonte, MG: Arraes Editores, 2016.

HARTLEY, Trevor; DOGAUCHI, Masato. Convention of 30 June 2005 on choice of court agreements: explanatory report. Haia: Secretariado Permanente da Conferência Scheveningseweg 6, 2005. Disponível em: 
$<$ https://assets.hcch.net/docs/a90b5aea-89cf-4541-b7b7-

e5e960703845.pdf>. Acesso em: 03 de janeiro de 2017.

JATAHY, Vera Maria Barreira. Do conflito de jurisdições: a competência internacional da justiça brasileira. Rio de Janeiro, RJ:

Forense, 2003.

STRENGER, Irineu. Direito processual internacional. São Paulo, SP:

LTr, 2003.

Projeto de Sentenças Estrangeiras da Conferência de Haia: por um regime global de circulação internacional de sentenças em matéria Civil e Comercial Foreign Judgments Project of Hague Conference: for a global regime of international circulation of judgments on Civil and Commercial subjects

Submetido em: 2016-12-15

Aceito em: 2017-01-30 